\title{
NOTICIA DE UN MANUSCRITO «OLVIDADO» EN LOS FONDOS ÁRABES ESCURIALENSES \\ (MS. ÁR. $174_{2(39 v)}$ )
}

Aurora CANO LEDESMA

Universidad Autónoma de Madrid

Con el calificativo de "olvidado" presento un opúsculo gramatical anónimo que fue omitido tanto por M. Casiri ${ }^{1}$ como por H. Derenbourg ${ }^{2}$ al elaborar sus respectivos catálogos de los fondos árabes de la Real Biblioteca de San Lorenzo de El Escorial.

La noticia de este "olvido" la he podido obtener al realizar la revisión de los mss. árabes con el fin de llevar a cabo la indización de los mismos ${ }^{3}$, actividad que lleva pareja el cotejo de la descripción codicológica que los autores antes mencionados ofrecen en sus catálogos.

En esas circunstancias me sorprendió, de una parte, la breve presentación que Casiri hacía del ms. 174 y, de otra, la más extensa - pero incompleta- de Derenbourg. Para precisar estas afirmaciones traigo a colación (en forma algo resumida) los pasajes de ambos catálogos:

\section{CASIRI $^{4}$ :}

"Codex multiplici manu exaratus, quo continentur:

$1 .^{\circ}$ Commentarius in ejusdem operis partem Centum Regentes, de Particulis videlicet, earumque usu, titulo Paraphrasis, auctore KHALEDO BEN ABDALLA BEN ABI BAKR ALANSARAEO, exaratus die 11, Schewali, anno Egirae 947, Christi 1540.

2. ${ }^{\circ}$ Commentarius ejusdem auctoris Khaledi in Grammaticam Giarumia exaratus die 21, mensis Moharrami, anno Egirae 953, Christi 1546.”

\section{DERENBOURG ${ }^{5}$ :}

"l. Commentaire sur les 'Cents Régents' de 'Abd-al-Qâhir Al-Djordjânî. Copie datée de 947 de l'Hégire (1556 ap. J.-Ch.).

${ }^{1}$ Casiri, M., Bibliotheca Arabico-Hispana Escurialensis, Madrid, 1767-1770, vols. I y II.

${ }^{2}$ Derenbourg, H., Les manuscrits Arabes de l'Escorial, París, 1884.

${ }^{3}$ Cano Lesdesma, A., Indización de los manuscritos árabes de El Escorial, Madrid, vol. I, 1996, vol. II, 1997.

${ }^{4}$ Casiri, M., op. cit., Tomo I, p. 40.

${ }^{5}$ Derenbourg, H., op. cit., Tomo I, pp. 103-104. 
2. $\quad$ (Fol. 46). Commentaire sur l'Adjourroûmiyya, par Khâlid ibn 'Abd Allâh ibn Abî Bakr Al-Azharî, Copie datée de 964 de l'Hégire (1556 ap. J.-Ch.)

\section{3. $\quad$ (Fol. 89). Paradigmes du verbe nasara."}

De la lectura del catálogo de Casiri se podría deducir que el ms. 174 sólo consta de dos obras, mientras que del catálogo de Derenbourg se obtienen más datos, ya que describe tres obras, precisa que el número de folios es de 98 y su grafía es "asiatique»; con esta descripción el lector que no pudiese verificar la consulta in situ daría por correctos los detalles consignados por Derenbourg. Ahora bien, realizada la consulta personal, puedo añadir los siguientes datos y precisiones:

a) La $1 .^{a}$ obra se inicia en el fol. $2 v$. (no consignado por Derenbourg), redactada en escritura oriental menuda, finalizando en el fol. 33r.

b) Los folios $34(\mathrm{r} / \mathrm{v})$ a $37(\mathrm{r} / \mathrm{v})$ están en blanco, aunque numerados.

c) El fol. 38r solamente presenta dos palabras, en letras de oro: “'arab Kitāb", siguiendo desde el fol. $38 \mathrm{v}$ al fol. $44 \mathrm{r}$ el opúsculo gramatical objeto de esta publicación, en escritura magrebí.

d) Los folios $44 \mathrm{v}, 45(\mathrm{r} / \mathrm{v})$ y $46 \mathrm{r}$ están en blanco y numerados.

e) En el fol. 46v comienza la 2. obra — según Derenbourg—, redactada en escritura magrebí, cuyo colofón aparece en el fol. 87v.

f) Los folios $88(\mathrm{r} / \mathrm{v})$ y $89 \mathrm{r}$ están en blanco y numerados.

g) En el fol. $89 \mathrm{v}$ se inicia la última obra, inconclusa, que llega hasta el fol. $98 \mathrm{v}$.

Una vez realizadas todas estas comprobaciones y precisiones, me sorprendió el hecho de que H. Derenbourg no hubiera consignado los datos de esta real y auténtica segunda obra, ya que si se consulta la introducción de su catálogo se lee:

L'identité et le sujet des oeuvres, l'identité et la date des auteurs, tels ont été mes objetifs constants, et pour les découvrir, j'ai puisé aux meilleures sources d'information... Toutes les fois que le manuscrit est muet sur le nom de l'auteur, j'ai, à l'exemple de Casiri, consulté la plus admirable des bibliographies encyclopédiques... ${ }^{6}$

De este pasaje se puede inferir el afán de precisión y exactitud que guió a Derenbourg en su ambiciosa labor y, por lo tanto, no es comprensible su actuación

${ }^{6}$ Derenbourg, H., op. cit., Tomo I, p. XXXVIII. 
al describir el códice 174, pues, como se podrá comprobar después (en la descripción del códice y de la obra), el opúsculo no es acéfalo, ya que tiene incipit, ni es inconcluso, pues tiene colofón, aunque no aporta nombre del autor ni data.

Por otra parte, al revisar concienzudamente el códice, he podido constatar la presencia de 'hojas de guarda' con notas bibliográficas sobre el contenido; la 2. y la $3 .^{a}$ son un auténtico fondo de información, redactadas en latín, donde se precisan las distintas obras que configuran este códice, de forma detallada y extensa. El tipo de letra es habitual en numerosos mss. árabes y se puede atribuir, con bastante probabilidad, a David Colville, intérprete de árabe de Felipe III; en 1617 llegó a la Biblioteca, trabajó 10 años en la catalogación de los manuscritos y explicó en el Colegio griego, hebreo y latín a los monjes ${ }^{7}$. Según G. Antolín, "también hizo un catálogo de los mss. arábigos y que en muchos de los mss. que todavía existen hay al principio notas bibliográficas. "

Las anotaciones concernientes al opúsculo "olvidado" se encuentran en la 3 . $^{\text {a }}$ guarda recto $y$, extractadas, dicen: " 2 - postea sequit ${ }^{\mathrm{r}}$ liber quinque foliis brevibus definitionibus explicans omnia qui in Gramaticis tractant ${ }^{\mathrm{r}}$... definitiones Gramaticales sine nomine authoris, breves, succint ${ }^{\mathrm{e}}$ et utiles... sinopsia pulcherrima reperies in principio libri columnis et literis..."

El extracto del pasaje latino confima claramente que su autor revisó a fondo todo el códice, pues en efecto, el opúsculo gramatical que nos interesa ocupa cinco folios, ofrece definiciones gramaticales breves, útiles, sin hacer constar el nombre del autor, y comienza con dos folios, a modo de índice temático, en forma de cuadro sinóptico a cuatro columnas, con los conceptos que después van a ser definidos.

$\mathrm{Si}$ se recuerda la descripción de Derenbourg -anteriormente mencionada-, cualquier lector que la consultase podría deducir erróneamente que la 1. ${ }^{a}$ obra (Comentario anónimo de los Cien regentes) finaliza en el fol. 45 , y que la 2. obra (Comentario a la Aŷurrümiya) se inicia en el fol. 46, sólo y exclusivamente DOS obras, nada más.

La omisión de Derenbourg produce un cierto desconcierto, ya que si David Colville (como he sugerido anteriormente) pudo haber plasmado esa descripción en las hojas de guarda, ¿cómo H. Derenbourg no la tuvo en cuenta al catalogar el códice? El hecho de estar redactada en latín no es óbice para Derenbourg, ya que

${ }^{7}$ La labor de D. Colville se encuentra recogida en el ms. H.I.11 con el título Raçon de lo que ay en la librería principal. Cf. Zarco Cuevas, J., Catálogo de los manuscritos castellanos de El Escorial, Madrid, 1924, Tomo I, p. 348.

${ }^{8}$ Antolín, G., La Real Biblioteca de El Escorial (Discurso leído en la Real Academia de la Historia en la recepción pública, en 5 de junio de 1921). Real Monasterio de El Escorial, 1921, pp. 80-81. 
en ocasiones cita e incluso corrige el catálogo de Casiri, lo cual confirma su conocimiento y dominio de esa lengua. Por lo tanto, subsiste la cuestión anteriormente planteada, el por qué fue omitido este opúsculo si ya Derenbourg puso de manifiesto su decidido propósito de ser minucioso y preciso en su catálogo; de otra parte, el exiguo número de folios de este opúsculo no es argumento que justifique su omisión, pues en ocasiones ha descrito fragmentos o bien opúsculos de menor extensión.

El códice está encuadernado en baqueta bruñida de color avellana, con unas dimensiones de 190x140 mm; lomo con cuatro nervaduras; en las pastas presenta dos recuadros que tienen en el centro, como super-libris, unas parrillas que son las armas del Monasterio, en recuerdo del martirio de San Lorenzo; los cantos están dorados y en el lateral aparece: ABDUL CAHIR EL IERANI, en sentido longitudinal, rematado con el $n .^{\circ} 28$. Este tipo de encuadernación, concordante con otros numerosos códices, es atribuida, con bastante verosimilitud, a Pedro del Bosque, durante el reinado de Felipe II; la ubicación del número de catalogación -28 - y del nombre del autor responde al sistema de colocación de los códices/libros en esa época, ya que se depositaban en los anaqueles de la librería con el lomo hacia el interior, de forma que quedaba a la vista del visitante el canto lateral dorado. De ese modo, se conseguían varios objetivos, entre los que destacan proteger el canto de las pastas, airear el papel de los folios y "deslumbrar» a los visitantes con su áurea apariencia.

Tras las tres hojas de guarda, descritas en el fol. $1^{\mathrm{r}}$, aparece la notación III.H.28, que responde a la primitiva catalogación y ubicación del códice. En el folio $1 v$ aparecen tres notas bibliográficas (árabe, castellano y latín) frecuentes en muchos mss. árabes escurialenses; tanto la nota árabe (en escritura magrebí cursiva) como la castellana son parcas en sus datos, ya que citan solamente las obras $1 .^{a}$ y $3 .^{a}$ del códice, mientras que el texto en latín remite a una ampliación que el lector encuentra en las guardas ya descritas.

A continuación paso a presentar las obras que configuran este códice:

1. a(2v) Comentario anónimo del tratado al-'Awāmil de 'Abd al-Qāhir alŶurȳānī, obra de la que existen otros ejemplares en los fondos escurialenses; redactado en escritura oriental muy menuda, presenta la técnica del reclamo (repetición, en margen inferior izquierdo del verso de un folio, de la primera palabra con la que se inicia el recto siguiente), técnica que es usual en los mss. de grafía oriental pero infrecuente en los de magrebí. En los márgenes presenta glosas de escritura oriental muy 
menuda, algunas cortadas al ser encuadernado el códice, finalizando en el folio 33r, con data de 947 (1540).

2. a(39v) Opúsculo gramatical anónimo, con basmala, redactado en escritura magrebí media, clara; los ff. 39v y 40r contienen el índice temático de los conceptos gramaticales que serán explicados a lo largo de la obra, finalizando en el fol. $44 \mathrm{r}$.

3. a(46v) Comentario de al-Azharī al tratado gramatical Aŷrrümiyya, redactado en escritura oriental de tipo medio, finalizando en el fol. $87 \mathrm{v}$ con la data 964 (1556), si bien Casiri da como data 953 (1546). Los folios 88 (r/v) y 89 r están numerados.

4. ${ }^{a}(89 v)$ Se inicia con basmala y es un opúsculo gramatical anónimo sobre paradigmas del verbo nașara, obra inconclusa, ya que al principio se indica que los capítulos de la conjugación son 35 , pero solamente ofrece el primero, dedicado al verbo trilítero en forma $1 .^{a}$; redactado en escritura oriental, de tipo medio, presenta una clara exposición metodológica.

En la catalogación que hace $\mathrm{H}$. Derenbourg del ms. 174 se aprecia otra omisión, la referente a la grafía de la 3. a obra - el comentario de al-Azharī a la Aŷurrümiyya - , ya que está redactado en escritura magrebí, aunque Derenbourg presenta todo el códice de escritura oriental, lo cual no se corresponde con la realidad. Dentro de la presentación codicológica del ms. 174 voy a detenerme en los detalles y precisiones de la segunda obra:

- Las dimensiones de la caja textual son de 150x85 mm, con 17 líneas por folio.

- Los ff. 39v y 40r constituyen el índice temático del opúsculo, todo él redactado en escritura magrebí, con reclamos, tinta roja para los grafemas consonánticos, cuadrícula y enmarque interior en azul, con el enmarque exterior en rojo y el tašd $\bar{l} d$ (tanto gramatical como ortográfico) en negro.

- Las cuestiones gramaticales aparecen resaltadas en el texto con respecto a las definiciones, utilizando tinta azul o roja para los grafemas consonánticos, mientras que el tašd $\bar{i} d$ y las vocales vienen en rojo o azul, de forma que con el contraste de colores queda puesto de manifiesto que es el inicio de un epígrafe. 
Las cuestiones gramaticales presentadas en el índice (ff. 39v y 40r) son 92, abarcando tanto el campo morfológico como el retórico; así se pueden encontrar los enunciados -y posterior definición-: Al-qiyās / la analogía, al-burhān / la demostración, al-ism / el sustantivo, al-fi'l/ el verbo, al-harf / la partícula, al-i'räb / la declinación, al-bina ' / lo indeclinable, al-tașrîf / la conjugación, al-ma 'rifa / la determinación, al-nakira / la indeterminación, al-mufrad / el singular, al-tatniya / el dual, al-yam '/ el plural, al-marfü' / el nominativo, al-manșüb/el acusativo, almaŷrūr / el genitivo, al-iḍăfa / el estado de anexión, al-mașdar / el nombre de acción, al-ištiqāq / la derivación, al- 'ämil / el regente, al-istitnā'/ la excepción, almudakkar / el masculino, al-mu'annat/ / el femenino, al-muttarid / el empleo extenso (de un término), al-isti ‘āra / la metáfora, al-șüra / la imagen, y así hasta 92 términos.

Si bien el autor suele ofrecer definiciones breves y concisas, como ocurre con la analogía: «Es la relación entre dos [conceptos] de manera que en la corrección del primero reside la del segundo y en la incorrección del segundo reside la del primero" <fol. 40v>; en el nombre: "Es una palabra que indica un concepto sin atribución del tiempo al expresar la información» <fol. 40v>; en el verbo: «Es una palabra que indica un concepto sujeto al tiempo al expresar la información" $<$ fol. 40v>; en la partícula: «Es una palabra que no expresa un concepto, antes bien, su concepto es [indicado] en otra palabra" <fol. 40v>; en la declinación: "Es el cambio del nombre por efecto de un regente" $<$ fol. $40 v>$. En otras ocasiones se extiende en la definición, marcando pautas o etapas de la secuencia de la misma, como sucede en la determinación: "Es lo privativo de algo debido a la característica literal que puede ser de dos formas: manifiesta o virtual; la primera puede ser alif y läm [el artículo] y la idăfa. La característica virtual es de tres formas: el nombre propio, el indefinido y el elíptico"<fol. 41r>; en la especie: (tras haber definido en el concepto anterior al género como «una categoría común a un concepto convencional y que se distribuye en especies diferentes»): "Es una de las diversas secciones del género, como el animal y el hombre, pues el género conlleva su especie, como cuando dices todo hombre es animal, mientras que el plural no rige uno sólo, así, al decir toda vaca [es] vacas, lo mismo que al decir todo hombre [es] hombres, ya que un [elemento] del género es especie» < fol. $42 r>$, en la comprobación: "Es lo referente al concepto en el que se da [lo contrario] de lo que es, como [sucede] con la mentira, que es la noticia de algo contrario a lo que es, mientras que lo comprobado a veces precisa de explicar una verdad, ya que toda mentira [puede estar] comprobada, [pero no] todo lo comprobado es mentira" <fol. 43r>. Al final del opúsculo retorna a las definiciones breves, precisas y concisas, como ocurre con la expresión [oral]: «Es una palabra que sale de la boca» <fol. 43r>; en la interrogación: «Es la demanda 
de información», en la información: «Es la demanda de atribución» <fol. 43r>; en la metáfora: "Son secciones del discurso de acuerdo a lo que son en origen, pero transformadas por la hipérbole» < fol. 43r>; etc.

Tras este breve repaso a algunas de las cuestiones gramaticales expuestas en el opúsculo, en sus diversas facetas (morfológicas, sintácticas, retóricas...), cabría detenerse a valorar su claridad expositiva, la economía del lenguaje cuando la cuestión gramatical se supone que es de sobra conocida, mientras que se hace prolija y extensa en otros apartados que entrarían en el ámbito de lo que se podría denominar la lógica del lenguaje. Todas estas precisiones podrían abocar a la elaboración de la siguiente hipótesis: el autor anónimo de este opúsculo quiso escribir un pequeño manual de gramática, con el objetivo de que fuese estudiado y aprendido, procurando que las definiciones fuesen claras, breves y útiles. De otra parte, la lectura de las cuestiones gramaticales y sus definiciones evocan los contenidos de la obra de Ibn Ŷinnī (m. 393/1001), sobre todo en el Kitāb alJașẩiṣ (consagrado a los fundamentos de la gramática árabe), y en el Kitab sirr sinā'at al-i'räb (tratado de fonética).

Este opúsculo «olvidado» no es el único manuscrito árabe escurialense omitido tanto por Casiri como por Derenbourg en sus catálogos, o bien que no fueron presentados de forma precisa en todos sus datos, etc., como se puede deducir de las secciones que denomino Acotaciones al catálogo de H. Derenbourg, con la que se inicia cada tomo de la Indización ya mencionada; dado que esta investigación está sin finalizar en el momento actual — falta el, tomo III-, es de suponer que circunstancias de omisión/olvido se puedan repetir.

\section{RESUMEN}

En este artículo se da noticia de la existencia de un opúsculo gramatical anónimo en los fondos árabes de la Real Biblioteca de San Lorenzo de El Escorial; sobre el citado opúsculo no hay información en los catálogos que hicieron tanto M. Casiri (1760) como H. Derenbourg (1884). Esta omisión queda subsanada con esta publicación, en la que se presenta la descripción codicológica del manuscrito, contenido y diversas particularidades del mismo.

\section{ABSTRACT}

Notice is given in this article of a small anonymous work on grammar in the Arabic collection of the Real Biblioteca of San Lorenzo de Escurial. Of the said work there is no 
information given in the catalogues of both M. Casiri (1760) and H. Derenbourg (1884). This omission is rectified with the present article in which a codicological description, contents and various particularities of the text are presented.
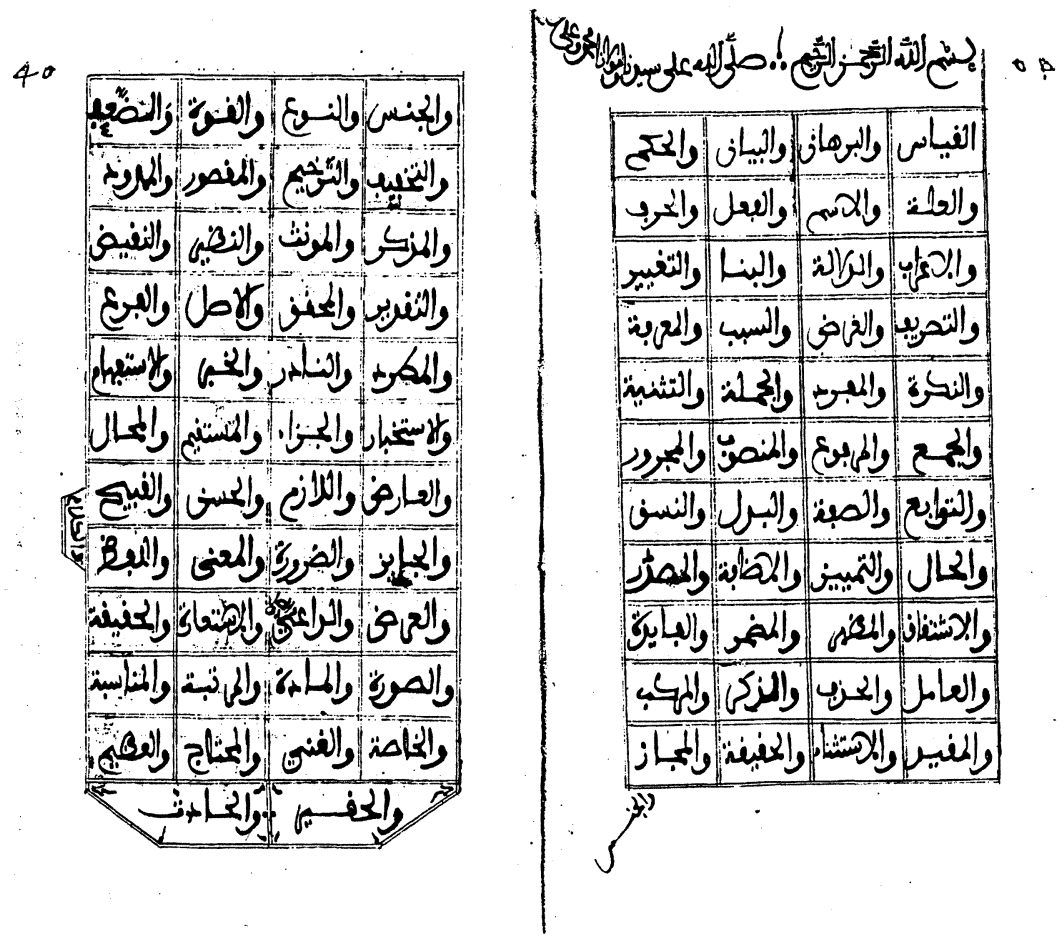